\title{
GUÍA DE HALLAZGOS POR PLANOS LINGÜÍSTICOS PARA EL COMENTARIO DE TEXTOS NO LITERARIOS EN BACHILLERATO
}

\author{
GUIDE OF FINDINGS BY LINGUISTIC AMBITS FOR THE \\ COMMENTARY OF NON-LITERARY TEXTS IN BACCALAUREATE
}

Jesús Eloy PÉREZ ALONSO*

Consejería de Educación. Comunidad de Madrid

Orcid: https://orcid.org/0000-0002-0765-7086

\begin{abstract}
Resumen
La práctica del comentario de texto no literario es uno de los objetivos fundamentales en la asignatura de lengua castellana y literatura en la etapa de Bachillerato. En esta tarea se ponen en juego los distintos planos o ámbitos de la lengua vinculándolos a un texto propuesto para el comentario. Pese a ello, los estudiantes encuentran grandes dificultades para identificar y estructurar las características lingüísticas presentes en los textos y los docentes se enfrentan al reto de ofrecer respuestas didácticas a este ejercicio. En este artículo se propone una herramienta para el comentario que se basa en una guía de hallazgos en los distintos planos lingüísticos (morfológico, sintáctico, léxico-semántico y pragmático). De forma secuenciada, se pretende que los estudiantes analicen los rasgos lingüísticos en cada uno de estos ámbitos en una triple dimensión (presencia, localización y finalidad), es decir, identificándolas, ejemplificándolos y justificando su uso en función de la intención del texto propuesto para el comentario. Para ello es necesario realizar varias tareas antes de afrontar el comentario y durante la práctica del mismo. Finalmente, se describe la estrategia y la propuesta de enseñanza-aprendizaje, así como su secuenciación y aplicación pedagógica a lo largo de un curso académico utilizando diversas estrategias metodológicas que ayudan a sistematizar el trabajo y ponerlo en común dentro del grupo-aula.
\end{abstract}

Palabras clave: guía práctica; texto no literario; comentario de texto; didáctica; lengua castellana. 


\begin{abstract}
The non-literary text commentary is one of the fundamental objectives in the contents of Spanish Language and Literature subject at the Baccalaureate stage. In this task, the different levels or domains of language come into play linking them to a text proposed for commentary. In spite of this, students find great difficulties to identify and structure the linguistic characteristics present in the texts and teachers face the challenge of offering didactic answers to this kind of exercise. In this article a tool for the commentary is proposed that is based on a guideline of findings in the different linguistic ambits (morphological, syntactic, lexical-semantic and pragmatic). Gradually, it is intended that students analyze the linguistic features in each of these areas in a triple dimension (presence, location and purpose), identify, exemplify and justify their use depending on the text target. For this purpose, it is necessary to carry out several tasks before facing the commentary and during its practice. Finally, the teaching-learning strategy and proposal is described, as well as its sequencing and pedagogical application throughout an academic year using various methodological strategies that help to systematize the work and share it within the classroom group.
\end{abstract}

Key Words: practical guide; non-literary text; text commentary; teaching; Spanish 


\section{INTRODUCCIÓN Y JUSTIFICACIÓN}

Uno de los retos más importantes del docente de Lengua castellana y Literatura en la etapa de Bachillerato es la tarea de enseñar la práctica del comentario de texto (en adelante, CT) a sus estudiantes. Afrontar este proceso supone repasar los conocimientos teóricos de la asignatura en sus distintos bloques $\mathrm{y}$, lo que es más importante, identificarlos en el texto propuesto para el comentario, así como discernir la intencionalidad de su uso. En definitiva, comentar un texto "supone la valoración equilibrada de su contenido y de su forma, de su fondo ideológico o psíquico y de sus valores expresivos o estilísticos" e "implica un magnífico ejercicio mental de observación, de penetración y análisis" (Pérez Rioja, 1975: 95).

Así pues, el objetivo de un CT lingüístico no es diseccionar con frialdad un texto ni limitarse a catalogar los rasgos que presenta, sino descubrir las motivaciones de su empleo de forma interpretativa. La cuestión radica en superar el análisis de un texto para profundizar en el comentario, que "se centra en sus aspectos más importantes o atractivos, o en aquellos que interesan en función de los objetivos propuestos" (Romero Blázquez, 1998: 379), en conseguir llevar el estudio del texto hacia la síntesis, ya que:

el comentario lingüístico supone analizar el funcionamiento de la lengua [...]; posteriormente se intenta llegar a una síntesis, cuya fórmula general sería la siguiente: el texto en cuestión dice lo que dice en virtud de la particular realización del sistema lingüístico que en él se observa (Girón, 1982: 19).

El comentario de texto es una herramienta de larga tradición en la educación secundaria y se considera "la apuesta educativa más representativa de la década de los setenta en su intento de establecer un modelo didáctico estable que sustituyera al predominante a lo largo del siglo" (Colomer, 1996: 142). Prueba de su vigencia es que en la actualidad la práctica del CT no literario constituye una parte fundamental de los objetivos pedagógicos de la etapa de Bachillerato y en muchas de las comunidades autónomas forma parte de la prueba de acceso a la universidad.

En este artículo ofrecemos una metodología de análisis, dirigida al alumnado y al personal docente de la asignatura de Lengua castellana, que pondrá el foco en las características lingüísticas que pueden presentarse en este tipo de textos. Nos centraremos en diversos aspectos de cuatro planos o ámbitos: morfológico, sintáctico, pragmático y léxico-semántico. Asimismo, teniendo en cuenta que "el alumnado tiene dificultades para concretar los elementos lingüísticos que deben tener en cuenta en un texto" (López, 2011: 85 ), nuestro objetivo es ofrecer una guía para rastrear los rasgos lingüísticos que puedan aparecer, asignarlos a su plano o ámbito correspondiente y valorarlos al servicio de la intención comunicativa del texto.

En general, los obstáculos que el alumno encuentra para identificar las características lingüísticas y estilísticas más sobresalientes de los textos propuestos para el comentario se hallan en la falta de práctica a la hora de localizar los recursos empleados en el texto y la relación con su intención comunicativa, así como en la precisión y conocimientos que se requieren a la hora de manejar conceptos lingüísticos teóricos e identificarlos en la inmensidad de un texto.

Es indiscutible que existen muchos métodos a la hora de afrontar un CT y la bibliografía al respecto es tan amplia como variada. En ella encontramos desde manuales prácticos repletos de ejemplos hasta monografías más teóricas que se centran en aspectos muy concretos. Con este artículo no pretendemos enmendar la plana a ninguno de los 
materiales ya existentes, sino formular una guía alternativa que resulte útil y práctica para la identificación, ejemplificación y determinación del valor de uso de dichos rasgos lingüísticos y estilísticos. Nuestro objetivo es proporcionar unas pautas para articular los diversos hallazgos que pueden y suelen jalonar los textos no literarios propuestos para el comentario. Así pues, el resultado de nuestra propuesta es brindar un cuadro-guía, que incluimos en la tabla 1, como resultado de un método globalizador y sistematizador que debiera ser aplicado de forma adaptada para evitar que encorsete al estudiante a la hora de comentar un texto porque "el CT actual propone una flexibilidad máxima, siendo capaz de adaptarse al objeto discursivo o didáctico [...] es, efectivamente, una actividad con unas posibilidades incuestionables en la educación literaria y lingüística" (López Río, 2009: 16)

Tendremos siempre presente que la finalidad principal de un CT es desentrañar el sentido de un escrito esclareciendo las ideas, conceptos y técnicas usadas, pero sin olvidar que la redacción del mismo deberá estar presidida por la corrección en la expresión escrita, la claridad y precisión, la riqueza léxica y el cuidado de la organización sintáctica y textual, sin renunciar a cierto grado de originalidad. Por otro lado, y como es lógico, en función de las diferentes tipologías de textos (científico-técnicos, humanísticos, periodísticos, publicitarios, jurídico-administrativos...) los rasgos presentes en los textos variarán, pero las pautas globales para realizar el CT resultarán similares.

En definitiva, nuestro modesto propósito no es presentar teorías ni conceptos sobre el CT, sino, por el contrario, ofrecer una herramienta que sirva como punto de partida para redactarlo y que, paso a paso, introduzca al alumnado en el proceloso mundo de la búsqueda y hallazgo de las características lingüísticas de un texto a través de unas pautas articuladas en torno a un guion que permita que fije su atención en diversos aspectos que, si se presentan de forma recurrente, merecerán ser comentados. El resultado es un cuadro que ofrecemos en la tabla 1 y en el que, estructurados a través de planos de análisis (morfológico, sintáctico, léxico-semántico y pragmático), se recorren los posibles hallazgos que pudieran presentarse en los textos que vayamos a comentar.

\section{METODOLOGÍA: ESTRUCTURACIÓN Y TAREAS}

En este apartado secuenciaremos la aplicación de nuestra guía para el comentario de texto destacando algunas tareas previas, así como una triple dimensión que tendremos en cuenta en el momento de la realización del mismo.

\subsection{Antes de afrontar el comentario de un texto}

Se considera imprescindible leer al menos tres veces el texto, algo que tradicionalmente se ha venido señalando en cualquier manual práctico para el comentario de texto y que, como subraya Sánchez, (2013: 32) es la base del pensamiento crítico. Para ello utilizaremos tres niveles de lectura:

1. Lectura comprensiva: proporciona una primera aproximación al texto de la que suele extraerse una visión global del mismo y de su significado.

2. Lectura reflexiva: permite entender el texto con mayor profundidad, seguir su hilo conductor y percibir cuáles son las palabras e ideas claves. 
3. Lectura analítica: desde la tercera y sucesivas lecturas se ve facilitada la localización de los recursos y la organización del texto: sus características y estructura (idea principal, secundarias y conexión entre ellas).

A partir de la segunda lectura es muy recomendable subrayar aquellas palabras o frases que resulten más reveladoras o que evidencien las técnicas expresivas que emplea el texto. También conviene marcar la división por partes que hayamos observado y esbozar las características más evidentes y recurrentes que vayamos observando. Otro recurso útil es numerar en el margen las líneas de 5 en $5(5,10,15,20 \ldots)$, lo que nos permitirá citar con mayor rapidez el punto concreto en el que aparece algún elemento a la hora de ejemplificarlo, demostrando así su presencia en el texto.

\subsection{Afrontando el comentario de texto: triple dimensión de las características, intención y estructuración por planos}

Llegados a este punto, conviene insistir en que un CT no es un catálogo de recursos literarios ni tampoco una sucesión de afirmaciones sin justificación ni ejemplificación alguna y que, en ningún caso, deberemos centrarnos solo en la forma obviando el contenido, o viceversa. En este sentido, un comentario habrá de tener siempre una intención última probatoria; para ello, hemos condensado las seis preguntas que se formula García Elena (2010: 274-275) a la hora de comentar un texto no literario: qué se dice en el texto, quién lo dice, para qué lo dice, para quién lo dice, a través de qué medio lo dice, dónde lo dice y cuándo lo dice.

Así pues, a nuestro juicio, lo más interesante y recomendable es formular los rasgos que están presentes en el texto en una triple dimensión:

- Presencia: mencionar qué rasgos aparecen en el texto: hallazgos en el ámbito morfológico, sintáctico, léxico-semántico y pragmático (Domínguez, 1977: 21).

- Localización: indicar dónde aparecen en el texto: párrafo concreto, número de línea, citas entrecomilladas... En este sentido, recordemos que "las referencias al texto deben ser constantes, pero equilibradas, puesto que un comentario no puede ser ni una paráfrasis del texto ni tampoco una excusa para exponer conceptos teóricos" (Cuenca, 2009: 45).

- Finalidad: formular para qué se usan en el texto, buscando desentrañar su función e intencionalidad y conectándola con el objetivo que persigue el autor con el texto. Sin duda, esta dimensión resulta la más difícil porque implica cierta especulación que, en todo caso, siempre estará vinculada a la finalidad e intención comunicativa del propio texto y a los valores que pretende transmitir. No en vano

comentar un texto consiste en ir razonando paso a paso el porqué de lo que el autor ha escrito [...]. Explicar un texto es ir dando cuenta, a la vez, de lo que un autor dice y de cómo lo dice (Correa Calderón y Lázaro Carreter, 1974: 10).

En definitiva, el principal objetivo del CT tal y como lo concebimos es tener una intención probatoria, justificando las razones que han motivado el uso de esos recursos y evitando el mero catálogo de hallazgos sin su correspondiente interpretación ni ejemplificación. Por ello, cada afirmación deberá probarse a través de algún ejemplo o 
cita tomados del texto y, a continuación, tratar de demostrar su utilización en función de la finalidad que persigue el texto. De hecho:

Uno de los errores más frecuentes del comentario de textos, tanto literarios como no literarios, es el excesivo formalismo intrascendente. [...] ir entresacando del texto aquellos elementos formales más importantes con el fin de dotar al alumno de una estructura gramatical básica. Nadie duda de su importancia, pero todos los aspectos formales sólo adquieren su auténtica dimensión comunicativa a la luz de la finalidad del mensaje (García Elena, 2010: 273).

$\mathrm{Al}$ respecto, recordamos algunas recomendaciones para la práctica del CT en la etapa de Bachillerato como:

- Reflexionar sobre el texto (su forma y su contenido).

- Asociar nuestros conocimientos (fonético-fonológicos, morfológicos, gramaticales, léxico-semánticos, pragmáticos...) a lo que aparece en el texto.

- No perderse en cuestiones secundarias, tangenciales o ajenas al tema y al objeto del comentario.

- Huir del subjetivismo: evitando las aseveraciones contundentes, las posiciones categóricas y las opiniones personales y polémicas.

- Expresar nuestra interpretación de su intención comunicativa basándonos siempre en el texto.

En este sentido, concebimos esta parte del CT como una tarea que permite repasar una enorme variedad de conceptos lingüísticos que se han trabajado durante la etapa de ESO y en los que se profundiza durante el Bachillerato, poniéndolos en juego de forma práctica mediante su descubrimiento en el texto propuesto para el comentario. Al respecto, parece obvio que los hallazgos y características que se señalen deben ser suficientemente representativos, tanto porque demuestren la intencionalidad y tipología a la que responde el texto como porque aparezcan de forma recurrente. Así pues, obviaremos aquellos elementos que, aun existiendo, no sean reveladores ni aporten valor más allá de lo anecdótico o los que solo ofrezcan generalizaciones irrelevantes.

Al respecto, nuestro planteamiento supone proporcionar una guía pautada que ayude a orientarse a la hora de comentar un texto, brindando unas referencias o elementos en los que el alumnado pueda focalizarse para ir hallando rasgos lingüísticos pertenecientes a cada uno de los planos. Partimos de la consideración de que:

En la descripción de los fenómenos lingüísticos analizados, y en su interpretación y valoración posteriores, se puede operar [...] a partir de la distinción de tres planos metodológicos fundamentales: fonético-fonológico, morfosintáctico y léxicosemántico, que tipificarán sendas clases de comentarios lingüísticos (Solsona, 2014: 241).

Precisamente, pretendemos condensar la sucesión de siete planos -fonológico, morfológico, sintáctico, conectivo sintáctico-semántico, léxico, semántico y de integración global- (Marcos, 1977) en cuatro: fonético-fonológico, morfológico, sintáctico y léxico-semántico. A estos le añadiremos un quinto, el pragmático, en el que incluiremos todos aquellos elementos vinculados a la adecuación (reglas de uso), coherencia y cohesión (reglas del discurso). Desglosamos a continuación la relevancia de 
cada uno de ellos en lo que se refiere a un comentario lingüístico de un texto no literario en la etapa de Bachillerato:

1. Fonético-fonológico: excluiremos este apartado del comentario ya que no suele resultar relevante en la etapa de Bachillerato. Esto se debe a que está vinculado a las modalidades de entonación predominantes, los aspectos rítmicos o las figuras retóricas de carácter fónico (aliteración, onomatopeya, parónimos, rimas internas...), que apenas aparecen en textos no literarios.

2. Morfológico: nos centraremos en este plano en todo lo relacionado con las categorías gramaticales. En este sentido, las que dan más juego son sobre todo las variables. En primer lugar, los verbos, que exigen una atención en todos sus rasgos gramaticales, especialmente en el tiempo, la persona, el número, el modo y la voz; así como en su valor de uso. Por otra parte, los sustantivos también pueden ser indicadores interesantes en cuanto a sus diferentes clases (propios o comunes; individuales y colectivos; concretos y abstractos...). Asimismo, la presencia de adjetivos, su carácter explicativo o especificativo o el grado en el que se encuentren serán cuestiones de interés. En lo que se refiere a los determinantes y los pronombres, nos focalizaremos en los tipos que predominen (posesivos, demostrativos, indefinidos, numerales...)

3. Sintáctico: nos ocuparemos aquí de los enunciados del texto en general y de su estructura sintáctica en particular. Algunos aspectos destacables al respecto son la modalidad oracional predominante (enunciativa, interrogativa, exclamativa, exhortativas, desiderativas y dubitativas) y el tipo de sintaxis empleada (simple/compleja, coordinación/subordinación/yuxtaposición, tipos de coordinadas y de subordinadas que predominan...). También resultará reveladora la presencia de pasivas reflejas y/o de impersonales para ocultar el sujeto-hablante, así como el empleo de estructuras nominales y de oraciones atributivas, caracterizadas por su estatismo y su voluntad de definir conceptos.

4. Léxico-semántico: en este plano nos centraremos en el significado de las palabras. Uno de los aspectos más fácilmente visibles es si predomina un lenguaje denotativo (exposición) o connotativo (argumentación). Por otro lado, resulta conveniente identificar los campos semánticos utilizados y su organización en hipónimos, hiperónimos y cohipónimos. Otros conceptos y recursos relevantes son las familias léxicas, el empleo de arcaísmos, el posible uso de neologismos y tecnicismos, así como la presencia de rasgos dialectales. Finalmente, resulta imprescindible indicar el registro y nivel lingüístico que emplea el texto (culto, vulgar, coloquial, especializado o jergal, estándar...)

5. Pragmático: vincularemos este apartado a las propiedades textuales:

- Coherencia: estructura ordenada y desarrollo de los enunciados que ayuden a comprender el texto, importancia de la situación comunicativa... En este ámbito, 
un aspecto fundamental es identificar la estructura interna del texto: división por partes (no quedarse en la división externa y visual por párrafos) y la organización de las ideas (inductiva, deductiva, encuadrada o circular, paralela...)

- Cohesión: mecanismos de sustitución y recurrencia (repetición, sinonimia, antonimia, elipsis, perífrasis léxicas, símiles, metáforas, rodeos...) y empleo de elipsis. También estaremos especialmente atentos al uso de conectores oracionales, marcadores textuales $\mathrm{u}$ ordenadores del discurso y elementos deícticos (ya sean de persona - uso de pronombres personales, de posesivos y de terminaciones verbales-, de espacio -empleo de adverbios de lugar, de demostrativos y de expresiones que denoten localización espacial- o de tiempo uso de adverbios de tiempo y tiempos verbales empleados-).

- Adecuación: es la forma de comunicación adaptada al tema que afecta tanto a las intenciones comunicativas (informar, instruir o entender) como al grado de formalidad que el autor quiere dar al texto. Deberían incluirse en este apartado la intención comunicativa, las funciones del lenguaje (referencial, expresiva, conativa, fática, poética y metalingüística; hablaremos tanto de la predominante como de aquellas secundarias que resulten importantes), el tono empleado (neutro, crítico, humorístico, irónico...), las referencias crono-tópicas (tiempo y espacio) y los elementos que participan en el proceso comunicativo así como la relación existente entre ellos (presencia del emisor, del receptor/destinatario (y la relación entre ambos), condicionamiento del canal empleado, del código/s que use el texto, de la posible influencia del contexto...).

Como orientación general, recomendamos el hallazgo de tres o cuatro rasgos por cada uno de los planos lingüísticos señalados anteriormente, sacrificando la exhaustividad por la relevancia y la concreción. En este sentido, y con el objetivo de ayudar al alumnado a situar cada característica en su ámbito correspondiente, hemos elaborado un cuadro sinóptico, que incluimos en la tabla 1 al final del artículo y en el que de forma más rápida y visual se asocia cada elemento a su plano. No obstante, algunos rasgos pueden pertenecer a más de un plano o ámbito; así ocurre, por ejemplo, con los topónimos, que podríamos mencionar en el plano morfológico como sustantivos propios que son o en el pragmático por su valor espacial e importancia en lo que se refiere al contexto-situación que rodea al texto.

Además, en ocasiones, una misma característica puede presentarse de forma híbrida. Así por ejemplo, en un texto pueden predominar las funciones del lenguaje expresiva y conativa, si el autor del texto ofrece su opinión y pretende mover a la acción o convencer a los receptores. En otro sentido, un texto expositivo-argumentativo suele alternar párrafos en los que destaca la presencia de un léxico denotativo, frente a otros en los que abunda el léxico connotativo. Por tanto, siempre subrayaremos que los rasgos aquí expuestos no aparecen de forma lineal y aislada, sino que se interrelacionan constantemente, de manera que cada elemento se conecta y vincula con las demás características presentes en el texto, siempre al servicio de un objetivo comunicativo que guía todo el escrito. 


\section{DESCRIPCIÓN DE LA ESTRATEGIA O PROPUESTA DE ENSEÑANZA-APRENDIZAJE. SECUENCIACIÓN Y APLICACIÓN PEDAGÓGICA}

En todas las etapas de este proceso de enseñanza-aprendizaje aplicaremos una metodología basada en el trabajo cooperativo y en la reflexión sobre el texto partiendo del cuadro-guía de hallazgos por planos que proponemos (ver tabla 1); asimismo, dominarán la evaluación y retroalimentación crítica para compartir y reforzar conocimientos. Por ello, en cada uno de los cursos de la etapa de Bachillerato la secuenciación de contenidos se organizará en cuatro fases:

1. Repaso y consolidación teórica: con esta fase inicial, pretendemos ayudar al alumnado a que interiorice y tenga presentes los contenidos lingüísticos que habrán de tratar en el CT y que ya han sido vistos en cursos anteriores, repasándolos y razonándolos. Así pues, revisaremos de forma teórico-práctica todos los conceptos lingüísticos en cada uno de los planos, tarea para la que emplearemos las primeras semanas de cada curso.

2. Transferencia y funcionalidad: a continuación, identificaremos las características lingüísticas de forma guiada y acompañada dentro de un texto y las organizaremos en planos, ejemplificando y probando su utilidad. En este periodo, predominará la aplicación práctica y la justificación del uso que el autor o autora del texto hace de los mismos, subrayando el valor que tienen en el texto y su contribución al objetivo comunicativo perseguido.

3. Autonomía y esquematización de los rasgos lingüisticos: progresivamente, a partir del segundo o tercer mes del curso, cada estudiante irá repasando el cuadro-guía de hallazgos (incluido en la tabla 1) mencionando los rasgos que vaya identificando en los textos propuestos para el comentario. El resultado será colectivo en forma de trabajo colaborativo, conocimiento compartido y puesta en común ante el grupo-aula. De esta forma se pretende que cada estudiante vaya realizando la tarea de forma propedéutica para que llegue a desenvolverse individualmente con soltura.

4. Redacción escrita: fase ulterior en la que cada estudiante, a partir del cuadroesquema, deberá redactar los comentarios de forma ordenada en párrafos y estructurada por ámbitos lingüísticos, sin olvidar incluir los ejemplos debidamente citados en el texto, así como una interpretación sobre el valor y la razón de uso de cada una de las características halladas. En esta fase se redactarán diversos comentarios para lo que se requerirá temporalmente al menos la segunda mitad de cada curso académico de Bachillerato debido a:

las dificultades de expresión escrita del alumnado, al que le cuesta concienciarse de la situación comunicativa pertinente en este caso, sobre todo si tenemos en cuenta que se enfrenta a un nuevo género cuya intención y estructura desconocen, y el proceso de escritura con que debe hacerle frente (López, 2011: 80)

Algunas de las estrategias metodológicas que usaremos en la práctica del CT son: 
- La elaboración de borradores o esquemas previos individuales en formato cuadro que sirvan como base a la hora de redactar el apartado de las características lingüísticas y estilísticas.

- La puesta en común colectiva del CT entre los y las estudiantes del grupo-aula, lo que ayuda a compartir los conocimientos y los hallazgos, concienciar de los errores cometidos y, en consecuencia, a aguzar la mirada sobre el texto. Parece evidente que la interacción y el contraste de los diferentes puntos de vista enriquece la perspectiva del comentario y consolida los conocimientos lingüísticos que se aplican en este tipo de práctica.

- La organización en grupos de trabajo (con 4 miembros, uno por cada plano, y que se irán rotando entre estos al cambiar de texto) para elaborar colectivamente comentarios lingüísticos. Dichos grupos serán asimismo respecto del resto, grupos de crítica. En este sentido, su tarea consistirá en llevar a cabo una evaluación mutua a partir de la lectura y la crítica constructiva de los trabajos de los grupos ajenos. Los resultados de este análisis serán puestos en común ante el grupo-aula al completo.

- La consulta y lectura de CT ya resueltos, lo que permite conocer cómo trabajan otras personas, qué características y valores del texto han sido capaces de identificar y analizar así como juzgar críticamente si los hallazgos son relevantes y pertinentes.

- La organización de dinámicas de confirmación/refutación de características textuales, que aparecerán formuladas respecto a un texto y ante las que el alumnado deberá refrendar o negar su existencia y, en el primer caso, indicar en qué lugar del texto aparecen y cuál es la intención que se persigue con su uso.

No obstante, el/la docente deberá tener en cuenta el principal peligro que presenta el uso del cuadro-guía como herramienta pautada y auxiliar de apoyo a la realización de un CT: caer en el mero catálogo de recursos compartimentados en planos o niveles sin una vinculación global entre sí ni con el texto como totalidad organizada. Esto ocurrirá cuando el alumnado no sea capaz de trascender desde el hallazgo y la ejemplificación hacia la justificación de su uso (el porqué se emplea en el texto); sin duda, esta última es la vinculación más complicada, por lo que exigirá una práctica continuada y, por parte del docente, la insistencia en la funcionalidad de los rasgos lingüísticos hallados en virtud del objetivo comunicativo del texto.

\section{CONCLUSIONES}

Este artículo parte de una concepción pedagógica del CT basada en el análisis de los diferentes aspectos lingüísticos desde una perspectiva sincrónica, con un acercamiento pragmático y una metodología activa. Arrancamos de la idea de que no solo el conocimiento teórico sobre la lengua puede ayudar al alumnado a realizar un buen CT, sino especialmente la práctica con textos a través de la interacción en el grupo-aula con la guía y la orientación del docente.

En este sentido, la herramienta que proponemos en la tabla 1 es un cuadro-guía que busca facilitar la práctica del comentario de textos no literarios. Su objetivo fundamental es desentrañar el empleo de recursos lingüísticos de manera ejemplificadora y justificada. La metodología parte del repaso de los contenidos teóricos hacia su transferencia a la práctica del comentario de forma pautada y a través de la evaluación colectiva orientada 
a un desempeño individual que facilite esta tarea tan fundamental dentro de la etapa de Bachillerato.

Es obvio que esta práctica encuentra su justificación en la interrelación de los planos lingüísticos, de modo que partiendo del texto propuesto para el comentario, conectaremos el plano morfológico, sintáctico, léxico-semántico y pragmático con el objetivo comunicativo del texto. La labor ante la que nos encontramos tiene una triple dimensión (identificar, ejemplificar y justificar) y exige de sistematicidad, entrenamiento y secuenciación en cuatro fases para irla trabajando en cada uno de los cursos de Bachillerato. El resultado es una herramienta que pretende ofrecer una pauta para que el alumnado sepa en todo momento en qué elementos debe poner el foco a la hora de comentar las características lingüísticas de un texto para hallar de forma paulatina los rasgos recurrentes en cada uno de los planos (situados en las columnas del cuadro) e irlos confirmando mediante la cita de su existencia y la utilidad que brinda a la intención comunicativa. Tras su aplicación colectiva en el aula, gracias a la interacción con el resto del grupo, cada estudiante individualmente verá facilitada la tarea de interpretar los hallazgos, razonar la aparición de determinadas características recurrentes y relevantes así como preguntarse por qué están presentes esas y no otras.

Por otro lado, uno de los retos que queda pendiente para desarrollar en próximos artículos sería la elaboración de un cuadro-guía distinto para cada tipología concreta de textos (expositivos, argumentativos, narrativos, descriptivos, prescriptivos...). En cada uno de ellos se concretaría la constelación de características lingüísticas de cada gran familia textual, lo que permitiría focalizar el comentario con mayor precisión pautando los rasgos que podríamos encontrar.

Finalmente, consideramos que esta estructura por planos resultaría perfectamente adaptable a un comentario de textos literarios, como lo demuestran trabajos como el de Corriente Cordero (1990: 215) que a los planos semántico, pragmático comunicativo, fonético-fonológico y morfosintáctico añade el de la localización temporal (en la historia, en la tendencia o corriente literaria, en la trayectoria del autor y en la tradición).

Las diferencias entre el texto literario y otro tipo de textos son graduales, no sustanciales: usan el mismo código, con intencionalidades distintas pero no necesariamente opuestas que se reflejan en el uso de la lengua [...]. Es posible desarrollar un método de comentario válido para la comprensión de cualquier tipo de texto por su capacidad de resaltar las diferencias lingüísticas que gradúan la distancia comunicativa que marca cada modalidad textual (Martín Vegas, 2018: 2)

En conclusión, aspiramos a ofrecer un método que resulte útil para tomar conciencia de los rasgos lingüísticos presentes en un texto no literario y de su valor significativo. El objetivo es contribuir a orientar al alumnado en el hallazgo de características lingüísticas para estructurar la práctica del CT y marcar el camino hacia la redacción del mismo. 


\section{TABLA 1: CARACTERÍSTICAS LINGÜÍSTICAS Y ESTILÍSTICAS DE UN TEXTO: CATÁLOGO DE HALLAZGOS POR PLANOS}

\begin{tabular}{|c|c|c|c|}
\hline MORFOLÓGICO & SINTÁCTICO & LÉXICO-SEMÁNTICO & PRAGMÁTICO \\
\hline $\begin{array}{l}\text { Predominio de categorías: } \\
\text { - Sustantivos: propios, comunes, } \\
\text { concretos, abstractos, individuales, } \\
\text { colectivos, in/contables... } \\
\text { - Adjetivos y su tipo: especificativos } \\
\text { o epítetos; grado en el que están, } \\
\text { gentilicios.... } \\
\text { - Otros complementos del nombre: } \\
\text { sintagmas preposicionales... } \\
\text { - Verbos: tipos (de acción, de estado, } \\
\text { de movimiento...); persona; tiempos } \\
\text { (diferencia entre pretéritos, valor } \\
\text { hipotético del condicional...); modos } \\
\text { (indicativo para una mayor } \\
\text { objetividad, subjuntivo para expresar } \\
\text { deseos, imperativo para órdenes...); } \\
\text { voz (activa, pasiva refleja, pasiva); } \\
\text { perífrasis verbales (tipos y valor). } \\
\text { - Adverbios (intensificadores o } \\
\text { complementos verbales; tipos). } \\
\text { - Pronombres (sobre todo los } \\
\text { personales, indefinidos, posesivos y } \\
\text { demostrativos). } \\
\text { - Determinantes: tipos más habituales } \\
\text { (omitir artículos) y valor. } \\
\text {-Usos desplazados: plural de cortesía, } \\
\text { empleo del usted... } \\
\text { - Predominio del sintagma nominal } \\
\text { (estilo más estático y ritmo narrativo } \\
\text { lento. Textos más descriptivos). } \\
\text { - Predominio del sintagma verbal } \\
\text { (estilo con mayor dinamismo yo } \\
\text { acción. Textos más narrativos). }\end{array}$ & $\begin{array}{l}\text { - Modalidad oracional: enunciativas } \\
\text { (afirmativa o negativa), interrogativas } \\
\text { (retóricas o no), exclamativas, } \\
\text { imperativas, dubitativas o desiderativas. } \\
\text { - Tipo de sintaxis: simple/compuesta } \\
\text { por coordinación/subordinación/ } \\
\text { yuxtaposición (y subtipos más } \\
\text { habituales). } \\
\text { - Pasivas reflejas o pasivas: sujeto } \\
\text { oculto u paciente. } \\
\text { - Oraciones impersonales: sin sujeto. } \\
\text { - Oraciones atributivas o de SV- } \\
\text { P.Nominal: vbo copulativo }+ \text { ATB } \\
\text { - Oraciones predicativas o de SV- } \\
\text { P.Verbal: vbo predicativo } \\
\text { complementos (cuáles predominan) } \\
\text { - Construcciones } \\
\text { subordinadas de formas no personales } \\
\text { sin enlace. } \\
\text { - Términos en aposición (SN-CN). } \\
\text { - Hipérbaton (busca destacar algún } \\
\text { elemento en posición inicial). } \\
\text { - Otras estructuras oracionales } \\
\text { recurrentes y/o paralelísticas. } \\
\text { - Asíndeton (+ velocidad) >< } \\
\text { Polisíndeton (+ lentitud). } \\
\text { - Paralelismos: isotopía gramatical. }\end{array}$ & 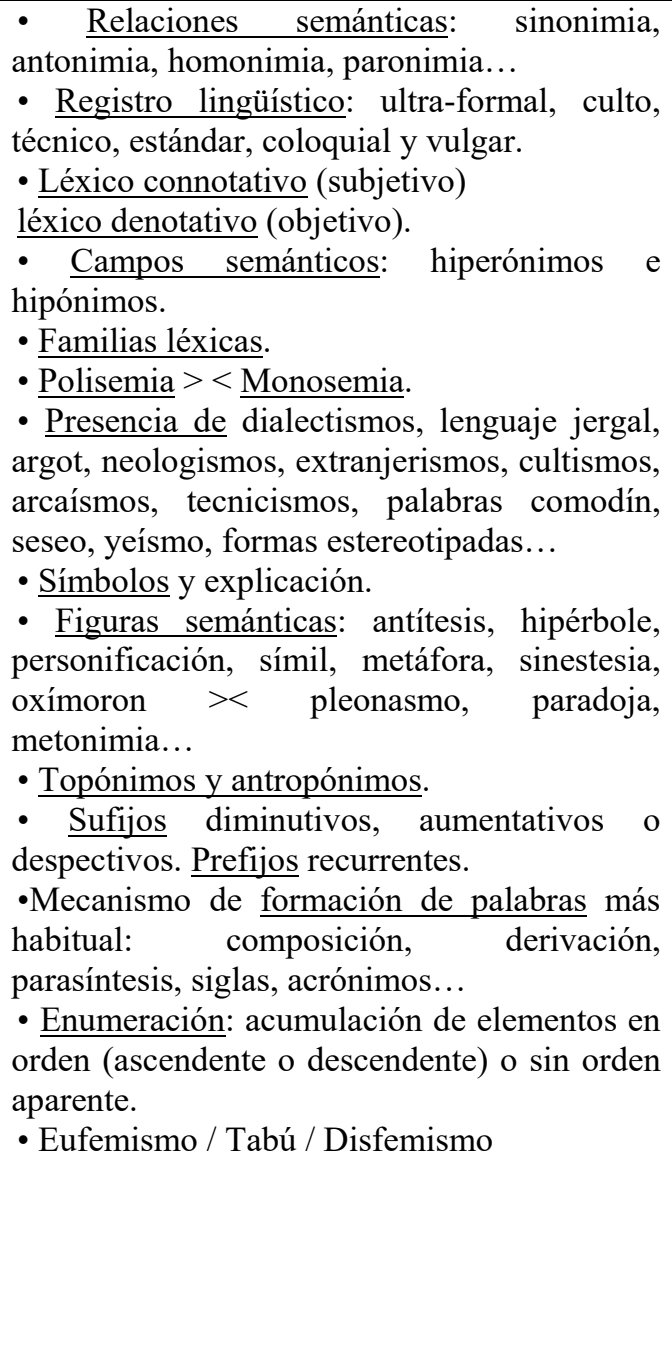 & $\begin{array}{l}\text { - } \text { Función del lenguaje: referencial, } \\
\text { expresiva, conativa, fática, metalingüística o } \\
\text { poética. } \\
\text { in Estructura (deductiva=analizante, } \\
\text { inductiva=sintetizante, paralela, encuadrada } \\
\text { o circular, cronológica...) y división por } \\
\text { partes. } \\
\text { - Elementos de la comunicación (emisor, } \\
\text { receptor, mensaje, canal, código, contexto...) } \\
\text { y adecuación. } \\
\text { - Intencionalidad del mensaje (didáctica, } \\
\text { estética, persuasiva, imperativa, crítica, } \\
\text { humorística, estética, irónica...) } \\
\text { - Eje crono-tópico (tiempo y espacio): fijar el } \\
\text { contexto. } \\
\text { - Leitmotiv: idea/elemento/motivo que se } \\
\text { repite a intervalos a lo largo del texto. } \\
\text { - Conectores y marcadores discursivos: tipos } \\
\text { y valor. } \\
\text { Elementos deícticos (pronombres, } \\
\text { adverbios de tiempo y lugar...): valor } \\
\text { contextual. } \\
\text { - Anáforas y catáforas. Progresión temática } \\
\text { (tema >< rema). } \\
\text { - Conocimiento enciclopédico del mundo. } \\
\text { - Implicaturas: información no explícita. } \\
\text { - Repetición, elipsis, sustitución por } \\
\text { sinónimos y pronominalización. } \\
\text { - Texto originalmente oral / escrito. } \\
\text { - Puntuación y formato (cursiva, comillas, } \\
\text { negrita, emoticonos...): tipografía } \\
\text { elementos gráficos. } \\
\text { - Tipos de argumentos usados (autoridad, } \\
\text { ejemplificación, emotivos, estadísticos...) }\end{array}$ \\
\hline
\end{tabular}




\section{REFERENCIAS BIBLIOGRÁFICAS}

Colomer, T. (1996). La evolución de la enseñanza literaria. Aspectos didácticos de Lengua y Literatura, 127-171. Zaragoza: ICE de la Universidad.

Correa Calderón, E. y Lázaro Carreter, F. (1974). Cómo se comenta un texto literario. Salamanca: Anaya.

Corriente Cordero, J.M. (1990). Hacia el comentario de texto como estrategia comunicativa: proyección docente. Cauce. Revista de Filología y su Didáctica, 13, 203-218.

Cuenca, M.J. (2009). El comentario de textos: planificación, textualización y revisión. Textos. Didáctica de la lengua y de la literatura, 52, 42-56.

Domínguez Caparrós, J. (1977). Introducción al comentario de textos. Madrid: Servicio de Publicaciones del Ministerio de Educación y Ciencia.

García Elena, G.L. (2010). El comentario de textos no literarios en la Educación Secundaria Obligatoria y en el Bachillerato. Publicacionesdidacticas.com, 4. http://publicacionesdidacticas.com/hemeroteca/articulo/004113/articulo-pdf

Girón Alconchel, J.L. (1982): Introducción a la explicación lingüística de textos. Metodología y práctica de comentarios lingüisticos. Madrid: Edinumen.

López, I. (2011). El comentario lingüístico de textos como mediador de las tareas de escritura. Bellaterra Journal of Teaching \& Learning Language \& Literature, 4 (1), 80-101.

López Río, J. (2009). El comentario de textos: estado de la cuestión. Lenguaje y textos, 30, 11-17.

Marcos Marín, F. (1977). El comentario lingüístico. Metodología y práctica. Madrid: Cátedra.

Martín Vegas, R.A. (2018). El comentario léxico del texto literario en la enseñanza de la lengua española. Linred: Lingüistica en la Red, 15. https://ebuah.uah.es/dspace/bitstream/handle/10017/34171/comentario_martin_LIN_ 2017_15.pdf? sequence $=1 \&$ isAllowed $=\mathrm{y}$

Pérez Rioja, J.A. (1975). Estilística. Comentario de textos y redacción. Bilbao: Liber.

Romero Blázquez, C. (1998). El comentario de textos literarios: aplicación en un aula de E/LE. En Celis, A. y Heredia, J.R. (Eds.), Lengua y cultura en la enseñanza del español a extranjeros: actas del VII Congreso de ASELE, 379-388. Cuenca: Ediciones de la Universidad de Castilla-La Mancha.

Sánchez Carlessi, H. (2013). La comprensión lectora, base del desarrollo del pensamiento crítico. Horizonte de la Ciencia, 3 (5), 31-38 https://dialnet.unirioja.es/descarga/articulo/5420526.pdf

Solsona Martínez, C. (2014). Didáctica de la lengua española. En J.L. Aliaga, et al. (Eds.), María Antonia Martín Zorraquino. Filología, Gramática y discurso. Artículos escogidos, 239-252. Zaragoza: Institución Fernando el Católico. 